\title{
Small Launch Vehicle Concept Development for Affordable Multi-Stage Inline Configurations
}

\author{
Benjamin R. Beers ${ }^{1}$ \\ Geocent - Jacobs ESSSA Group, Huntsville, AL, 35806, United States \\ Eric D. Waters ${ }^{2}$ \\ Jacobs ESSSA Group, Huntsville, AL, 35806, United States \\ Alan D. Philips ${ }^{3}$ and Grady E. Threet, Jr. ${ }^{4}$ \\ NASA, George C. Marshall Space Flight Center, AL, 35812, United States
}

\begin{abstract}
The Advanced Concepts Office at NASA's George C. Marshall Space Flight Center conducted a study of two configurations of a three-stage, inline, liquid propellant small launch vehicle concept developed on the premise of maximizing affordability by targeting a specific payload capability range based on current industry demand. The initial configuration, NESC-1, employed liquid oxygen as the oxidizer and rocket propellant grade kerosene as the fuel in all three stages. The second and more heavily studied configuration, NESC-4, employed liquid oxygen and RP-1 on the first and second stages and liquid oxygen and liquid methane fuel on the third stage. On both vehicles, sensitivity studies were first conducted on specific impulse and stage propellant mass fraction in order to baseline gear ratios and drive the focus of concept development. Subsequent sensitivity and trade studies on the NESC-4 concept investigated potential impacts to affordability due to changes in gross liftoff weight and/or vehicle complexity. Results are discussed at a high level to understand the impact severity of certain sensitivities and how those trade studies conducted can either affect cost, performance, or both.
\end{abstract}

\section{Introduction}

$\mathrm{W}$ ithin the last decade, the private sector has seen increased demand for affordable Small Launch Vehicles (SLVs) capable of delivering $10-450 \mathrm{lb}_{\mathrm{m}}(5-200 \mathrm{~kg}$ ) payloads to suborbital and Low Earth Orbit (LEO) destinations. A variety of potential cost effective designs have been proposed throughout industry, so NASA is seeking to expand its knowledgebase in order to help facilitate growth in the $100-150 \mathrm{lb}_{\mathrm{m}}(45-70 \mathrm{~kg})$ range as this capability is likely to yield the best opportunity, and therefore the highest customer base, as seen by said proposals.

The Advanced Concepts Office (ACO) Earth To Orbit (ETO) team at NASA's George C. Marshall Space Flight Center (MSFC) has developed two in-house concepts in order to better understand the viability of those proposals set forth by private entities. The focus of this particular investigation was to establish generic but affordable threestage, inline, liquid propellant vehicle concepts that yield low Gross Liftoff Weight (GLOW) while ultimately targeting the aforementioned payload capability range. A separate study underway within ACO is the investigation of an optimized clustered, multi-stage, liquid propellant vehicle concept that utilizes common core boosters, like that of the Delta IV Heavy as shown in Ref. 1, to achieve orbit. In using existing and near-term technologies, NASA has gained insight into what generic and affordable SLV concepts may resemble under the Ground Rules and Assumptions (GR\&As) outlined in the subsequent section.

\footnotetext{
${ }^{1}$ Aerospace Engineer, Advanced Concepts Office, George C. Marshall Space Flight Center/ED04, AIAA Professional Member.

${ }^{2}$ Engineer/Scientist Advanced Concepts Office, George C. Marshall Space Flight Center/ED04.

${ }^{3}$ Aerospace Engineer Advanced Concepts Office, George C. Marshall Space Flight Center/ED04.

${ }^{4}$ Lead Aerospace Engineer, Advanced Concepts Office, George C. Marshall Space Flight Center/ED04.
} 


\section{Launch Vehicle Concept Definitions}

All concepts and configurations discussed herein were developed using a suite of preexisting tools established by NASA: INTegrated ROcket Sizing (INTROS) and Launch Vehicle Analysis (LVA) via MSFC and Program to Optimize Simulated Trajectories (POST) via Langley Research Center, which was actually implemented by MSFC. ${ }^{2,3}$ Since INTROS was originally built to design larger launch vehicles like those of the Delta and Atlas families, it was necessary to refine the tool with more appropriate Mass Estimating Relationships (MERs) for select subsystems as to facilitate the designs of the NESC-1 and NESC-4 SLV concepts described below. The updated subsystem MERs include: stage separation, Thrust Vector Control (TVC), propulsion feed and pressurization systems, and avionics. Structural mass estimates were made based on the materials quoted from said proposals.

\section{A. NESC-1 Ground Rules and Assumptions (GR\&A)}

The NESC-1 baseline concept was established using the GR\&As listed in Fig. 1. Liquid oxygen (LOX) and rocket propellant grade kerosene (RP-1) were employed in all stages due to their availability from current industry demands and were assumed to yield 300 seconds of specific impulse $\left(\mathrm{I}_{\mathrm{sp}}\right)$ at a conservative Mixture Ratio (MR) of 2.77. ${ }^{4}$ All propulsion systems were pressure-fed by Helium in order to impart the propellant tank pressures shown. Thrust levels were based on conceptualized engines where corresponding engine masses were predicted using a MER built from both NASA and industry heritage hardware. Keeping affordability in mind, it is possible that thrust levels could be achieved either by a single engine or a cluster of smaller ones, however system complexity and thus cost would be affected. Initial diameters of $50 \mathrm{in}$. $(4.17 \mathrm{ft})$ for the first and second stage and $26 \mathrm{in} .(2.17 \mathrm{ft})$ for the third stage were chosen as an arbitrary starting point. The Mass Growth Allowance (MGA) and Safety Factor (SF) shown are standard values as defined by ACO.

\begin{tabular}{|c|c|c|c|}
\hline Item & Stage 1 & Stage 2 & Stage 3 \\
\hline \multicolumn{4}{|c|}{ Propulsion } \\
\hline Propellants & LOX/RP-1 & LOX/RP-1 & LOX/RP-1 \\
\hline Mixture ratio, MR & 2.77 & 2.77 & 2.77 \\
\hline Thrust $\left(b_{f}\right)$ & 55,000 & 18,000 & 1,000 \\
\hline Specific impulse, $I_{s p}(s e c)$ & 300 & 300 & 300 \\
\hline Propellant feed system type & Pressure-fed & Pressure-fed & Pressure-fed \\
\hline Propellant tank pressures (psia) & 550 & 550 & 250 \\
\hline \multicolumn{4}{|c|}{ Structures } \\
\hline Vehicle diameter (ft) & 4.17 & 4.17 & 2.17 \\
\hline Safety factor & 1.4 & 1.4 & 1.4 \\
\hline Mass growth allowance, MGA (\%) & $\begin{array}{c}\text { batt, avionics }=25 \\
\text { all other }=18\end{array}$ & $\begin{array}{c}\text { batt, avionics }=25 \\
\text { all other }=18\end{array}$ & $\begin{array}{l}\text { batt, avionics }=25 \\
\text { all other }=18\end{array}$ \\
\hline Vehicle structural material & IM7/877 & IM7/877 & IM7/877 \\
\hline \multicolumn{4}{|c|}{ Trajectory } \\
\hline Orbit type / delivery altitude (nmi) & \multicolumn{3}{|c|}{ Circular / 200} \\
\hline Inclination (deg) & \multicolumn{3}{|c|}{28.5} \\
\hline
\end{tabular}

Figure 1. NESC-1 Baseline Concept Ground Rules and Assumptions.

The standard ACO payload shroud geometry was scaled down from larger launch vehicles and, since no hard requirements were provided, the cylindrical section length was adjusted to maintain a standard payload density of approximately $6.5-7.5 \mathrm{lb} / \mathrm{ft}^{3}$ for all SLV configurations.

The ascent profile modeled for all NESC-1 concepts was a payload optimized, tower launched, due east trajectory out of Kennedy Space Center (KSC) to a $200 \mathrm{nmi}$ circular orbit. All three stages burn at $100 \%$ throttle until stage depletion with a four second coast that accounts for spent stage separation and the consequent stage ignition. Maximum acceleration and maximum dynamic pressure were unconstrained and allowed to be a product of the analysis.

The vehicle structural material was modeled as being comprised entirely of graphite epoxy composite (i.e., IM7/877 quasi-isotropic layup) with the exception of propulsion systems and propellant feed lines. The composite density used in this study was $\rho=0.065 \mathrm{bb}_{\mathrm{m}} / \mathrm{in}^{3}$ but is highly dependent on the layup scheme. In other words, all propellant tanks, skirts, intertanks, and interstages, in addition to the payload shroud are composite. Furthermore, the structural components were analyzed using a combined worst case approach such that each component experienced all major prelaunch and flight loads simultaneously. The prelaunch wind load was given a $1 \%$ risk value for exceeding peak wind at $\mathrm{KSC}$ with one day of exposure. ${ }^{5}$ Each component was built with a structural buckling knockdown factor of 0.65 and all pressurized structures were allowed to utilize pressure relief of flight loads. A 3-sigma dispersion was placed on the POST calculated angle of attack.

\section{B. NESC-4 Ground Rules and Assumptions (GR\&A)}

The NESC-4 baseline concept was established using GR\&As similar to those of the NESC-1 concept (Fig. 1 and Fig. 2) with the exception of the third stage. With the outlook that SLVs could serve as a technology development test bed for utilizing in situ resources elsewhere in the solar system, the third stage employed liquid methane fuel $\left(\mathrm{LCH}_{4}\right)$ and LOX which in a vacuum yields a higher ideal $\mathrm{I}_{\mathrm{sp}}$ of approximately 360 seconds at a higher MR of 3.45. It is worth noting that although this propellant combination has not yet been extensively flight proven, the technology is currently being developed through some small entity endeavors. 
In later trade studies within the NESC-4 configuration evolution, an expendable MK 70 Mod 1 ER strap-on Solid Rocket Booster (SRB) was modeled in quantities of two or four to increase payload capability as they are low cost and readily available from the military. The assumption was made that $99 \%$ of the propellant was consumed prior to jettison.

\begin{tabular}{|c|c|c|c|}
\hline Item & Stage 1 & Stage 2 & Stage 3 \\
\hline \multicolumn{4}{|c|}{ Propulsion } \\
\hline Propellants & LOX/RP-1 & LOX/RP-1 & $\mathrm{LOX}_{/} \mathrm{LCH}_{4}$ \\
\hline Mixture ratio, MR & 2.77 & 2.77 & 3.45 \\
\hline Thrust $\left(b_{f}\right)$ & 55,000 & 18,000 & 1,000 \\
\hline Specific impulse, $I_{s p}(s e c)$ & 300 & 300 & 360 \\
\hline Propellant feed system type & Pressure-fed & Pressure-fed & Pressure-fed \\
\hline Propellant tank pressures (psia) & 550 & 550 & 250 \\
\hline \multicolumn{4}{|c|}{ Structures } \\
\hline Vehicle diameter (ft) & 4.17 & 4.17 & 2.17 \\
\hline Safety factor & 1.4 & 1.4 & 1.4 \\
\hline Mass growth allowance, MGA (\%) & $\begin{array}{c}\text { batt, avionics }=25 \\
\text { all other }=18\end{array}$ & $\begin{array}{c}\text { batt, avionics }=25 \\
\text { all other }=18\end{array}$ & $\begin{array}{l}\text { batt, avionics }=25 \\
\text { all other }=18\end{array}$ \\
\hline Vehicle structural material & IM7/877* & IM7/877* & IM7/877* \\
\hline \multicolumn{4}{|c|}{ Trajectory } \\
\hline Orbit type / delivery altitude (nmi) & \multicolumn{3}{|c|}{ Circular / 200} \\
\hline Inclination (deg) & \multicolumn{3}{|c|}{28.5} \\
\hline
\end{tabular}

\section{A. Preliminary Sensitivity Studies}

The first set of sensitivity studies conducted on both the NESC-1 and NESC-4 concepts included $I_{s p}$ and PMF. Because some small entities are focusing on developing engines that utilize $\mathrm{LOX}$ and $\mathrm{LCH}_{4}$ propellants, this warranted that emphasis be placed more on the NESC-4 concept development rather than the NESC-1 concept which utilized LOX and RP-1 propellant on all three stages.

Figure 2. NESC-4 Baseline Concept Ground Rules and Assumptions.

Therefore, the $\mathrm{I}_{\mathrm{sp}}$ and PMF sensitivity studies were the only analyses conducted on the NESC-1 concept. Examining the vehicle's sensitivity to changes in PMF with respect to stage burnout mass provided a guide to drive subsequent trade studies by means of stage gear ratios. The gear ratio describes how sensitive the vehicle payload capability is to changes in each of the stage masses thereby providing a basis for whether or not certain trade studies are worthwhile. For example, a stage gear ratio is $6: 1$ if for every $6 \mathrm{lb}_{\mathrm{m}}$ of mass deducted from the stage results in $1 \mathrm{lb}_{\mathrm{m}}$ degradation in payload capability.

\section{B. NESC-4 Sensitivity and Trade Studies}

The delivery altitude effect on payload capability was the first sensitivity study conducted on the NESC-4 baseline concept. A circular orbit trajectory was maintained for each of the three delivery altitudes studied, including $200 \mathrm{nmi}, 160 \mathrm{nmi}$, and $120 \mathrm{nmi}$, which corresponded to the NESC-4A, NESC-4B, and NESC-4C configurations, respectively. The NESC-4C configuration was chosen as the baseline concept for the propulsion feed system trade study as it was assumed that SLV sized payloads would not typically necessitate high power requirements. Therefore, longer duration missions at higher altitudes were deemed unnecessary. As would be expected, the NESC-4C configuration also yielded the largest payload capability since stage propellant loads were held constant.

The NESC-4C configuration was originally developed with all Helium pressure-fed propulsion systems to induce first, second, and third stage propellant tank pressures of 550 psia, 550 psia, and 250 psia, respectively (Fig. 2). Pressure-fed propulsion systems require additional volume in the forward skirts to store pressurant tanks as well as stronger propellant tank walls to accommodate the higher pressures necessary to produce the required thrust. With a pump-fed propulsion system these attributes present a potential weight savings as long as it is not exceeded by the addition of an engine pump mass. The NESC-4D configuration employed pump-fed propulsion systems on the first and second stages and was chosen as the baseline configuration for the SF trade study since analysis showed this configuration to yield the lowest structural mass.

The standard SF for ACO concepts is 1.4 (Fig. 2) and was already employed in all previous configurations. The NESC-4E configuration studied the effects of lowering the SF from 1.4 to 1.2. Incorporating additional risk was deemed a worthwhile study since SLV sized payloads are not man-rated nor of extremely high value. However, the NESC-4D configuration was chosen as the baseline for the MGA sensitivity study.

As mentioned, the standard MGA as defined by ACO is $25 \%$ for batteries and avionics components and $18 \%$ for all other vehicle components (Fig. 2) and was also applied as such in previous configurations. In general, designing SLVs and their payload(s) are simpler with respect to the Space Shuttle and Curiosity rover, for example, and this comparison translates to a greater ability to track SLV MGAs which, in turn, could further translate to a substantial mass savings, although it inherently adds risk in the form of potential performance degradation if MGA is ultimately surpassed. Two configurations, NESC-4F and NESC-4G, were developed on this premise by reducing MGA by $50 \%$ and $75 \%$, respectively. Despite accepting an increase in risk, the NESC-4F configuration was chosen as the baseline for the subsequent group of sensitivity studies.

The next set of sensitivity studies consisted of the following: (1) LOX / RP-1 MR reduction, (2) first stage propellant load optimization, and (3) second and third stage propellant load optimizations. The first study, 
NESC-4H, reduced the first and second stage MR from 2.77 to 2.50 . The second study, NESC-4i, modified the NESC-4H configuration by reducing the first stage propellant load until it depleted at approximately ten seconds past the time of maximum dynamic pressure. Designing the liftoff stage such that it can at least overcome maximum dynamic pressure is typical of larger launch vehicles and was therefore considered to be the optimum design. ${ }^{1,6}$ Through a series of subsequent configurations, the last study, NESC-4N, reduced the second stage propellant load of the NESC-4i configuration and relocated its equivalent mass to the third stage thereby maintaining overall vehicle GLOW. Combining all three of the trade study results, the NESC-4N configuration was used as the baseline for the vehicle diameter sensitivity study.

The NESC-4N configuration studied the effects of reducing the first and second stage diameters while increasing overall length in order to maintain vehicle GLOW. The NESC-4N baseline configuration was designed with a $4.17 \mathrm{ft}$ diameter first and second stage. Both stage diameters were equally decremented to $4.00 \mathrm{ft}$ and $3.85 \mathrm{ft}$, NESC-4N.2 and NESC-4N.3, respectively, and then finally to $3.30 \mathrm{ft}$ for the NESC-4N.4 configuration to optimize $\mathrm{L} / \mathrm{D}$. The interstages and propellant tank forward and aft skirts were shortened according to the decreased height of the propellant tank domes due to the change in diameter. In doing so, the original interstage and intertank lengths were held constant as in the NESC-4N configuration. The NESC-4N.4 configuration was used as the baseline for upper stage thrust optimization sensitivity studies.

Thrust sensitivity studies were conducted on the second and third stages in order to optimize thrust for the NESC-4o and NESC-4P configurations, respectively. The NESC-4P configuration was built on the results of the NESC-4o thrust study and was therefore used as the baseline for the SRB trade studies.

The next group of trade studies focused on examining the payload capability effects when adding SRBs in quantities of two and four, NESC-4Q and NESC-4R, respectively. Secondary emphases were placed on exchanging passive (NESC-4Q and $-4 \mathrm{R}$ ) for active (NESC-4Q.2 and -4R.2) guidance systems, or TVC for fins, on the first and second stage and tower (NESC-4Q.2 and 4R.2) for rail (NESC-4Q and 4R) launch systems. The third stage did not include fins as the vehicle would be sufficiently high in the atmosphere such that aerodynamic forces are negligible. The fins were solid and, like the vehicle, were comprised entirely of graphite epoxy composite. An additional trade study, NESC-4S, was also conducted using the original vehicle scarring from the NESC-4Q.2 configuration to determine payload capability upon SRB removal. The NESC4Q configuration was chosen as the baseline for the final study, targeting a $100 \quad \mathrm{lb}_{\mathrm{m}}$ payload capability.

The final sensitivity study, NESC-4T, consisted of reducing each of the first and second stage propellant loads equally in order to target a $100 \quad \mathrm{lb}_{\mathrm{m}}$ payload capability. The only modification made to this configuration was the addition of hollow graphite epoxy composite fins for both stages.

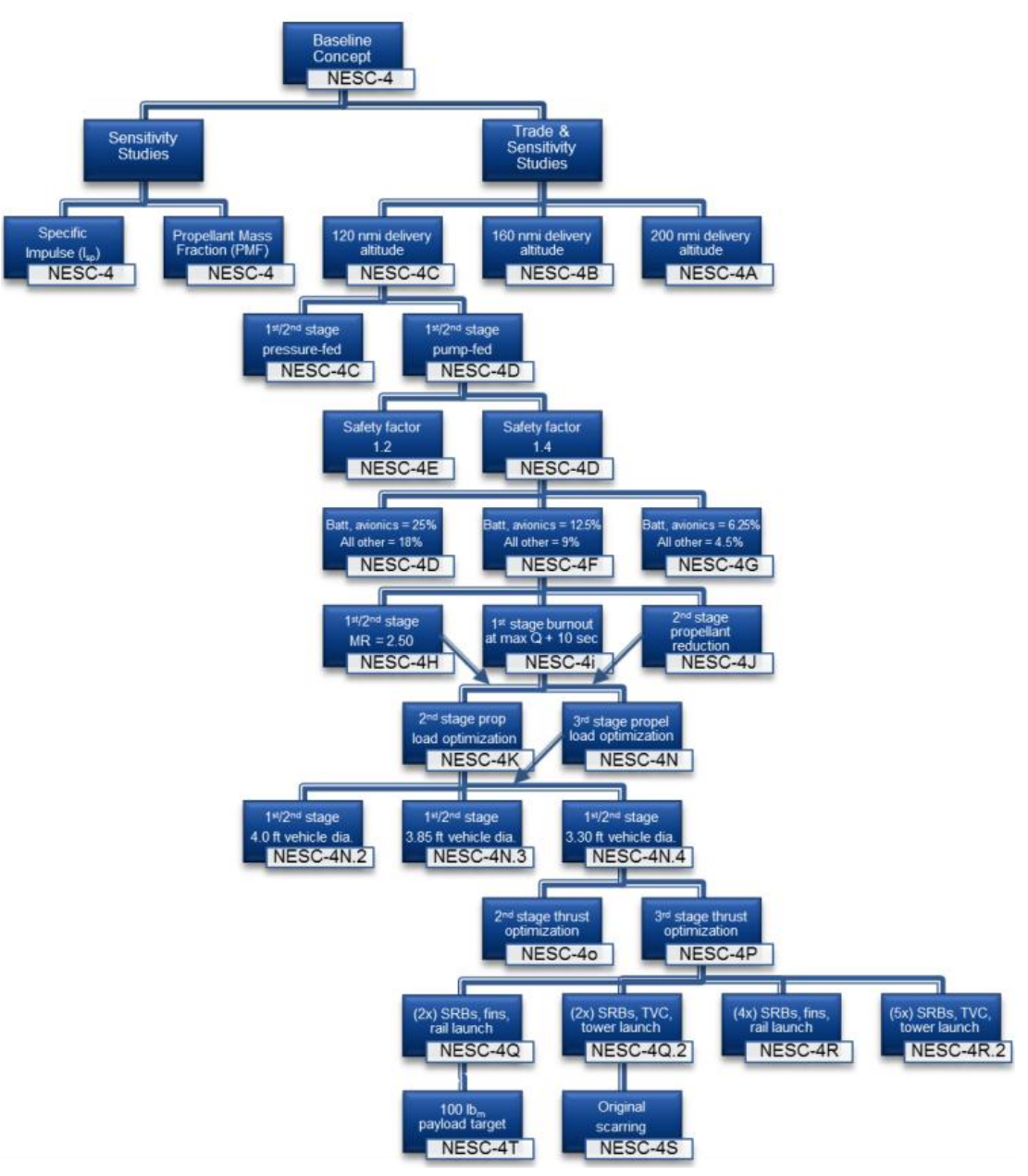

Figure 3. NESC-4 Concept Evolution 
A graphic representation of the aforementioned vehicle evolution path is shown in Fig. 3 while Fig. 4 depicts the NESC-1 and NESC-4 baseline configurations and the culminating, fully optimized NESC-4T configuration according to this study.

\section{Results and Discussion}

\section{A. Preliminary Sensitivity Studies}

The first sensitivity study concentrated on payload capability versus changes in PMF with respect to burnout mass. It is important to remember the following: (1) in comparing the NESC-1 and NESC-4 configurations, the third stage propellant changes from LOX and RP-1 to LOX and $\mathrm{LCH}_{4}$, (2) the shroud jettison between both configurations always occurs during the second stage burn, and (3) when adjusting the PMF of a given stage, the other stages are held constant such that payload capability was free to float.

As the NESC-1 first stage PMF increased by $2 \%$ thereby effectively adding performance to the stage, its payload capability increased by $16 \mathrm{lb}_{\mathrm{m}}$ to a total of $91 \mathrm{lb}_{\mathrm{m}}$ (Fig. 5). Similarly, if PMF was increased in the third stage by $2 \%$ then the payload capability further improved by $39 \mathrm{lb}_{\mathrm{m}}$ to achieve $114 \mathrm{lb}_{\mathrm{m}}$. The impact to payload capability was greater when the PMF was

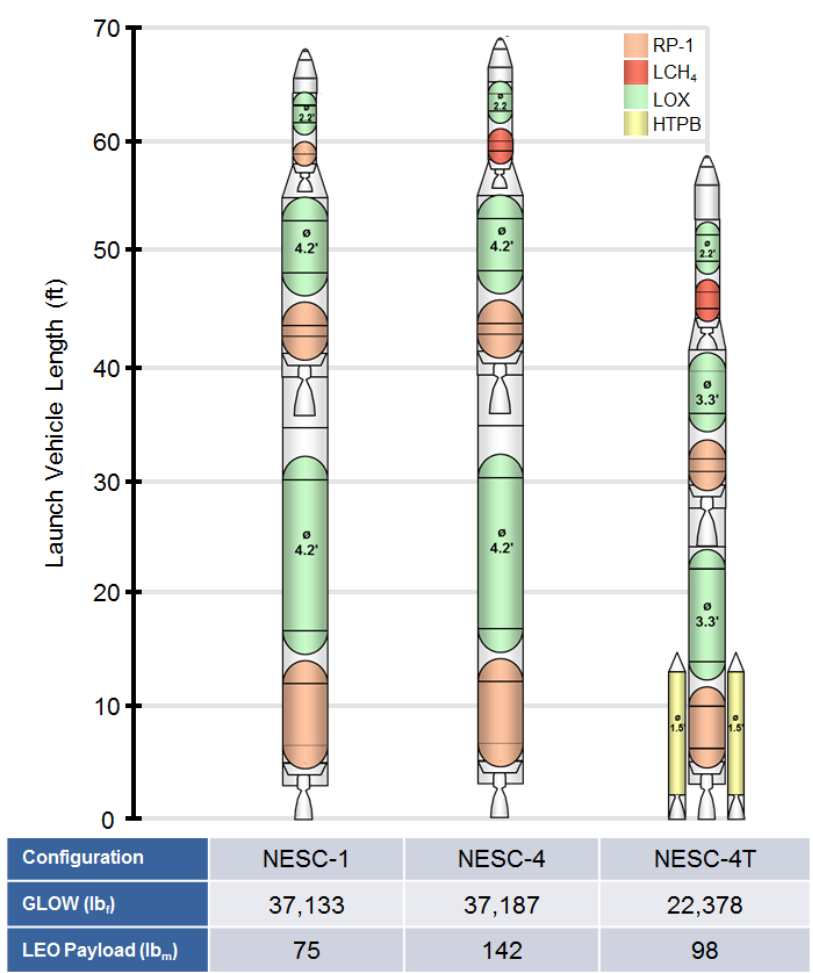

Figure 4. Baseline and Final Configurations. increased on the third stage due to it having a lower gear ratio (Fig. 7). In other words, although the mass differential is substantially higher on the first stage than on the third when adjusting PMF, it takes a larger mass percentage change in the first stage than it does on the third to dramatically affect payload capability. This notion can perhaps be seen more clearly by looking at the slopes in Fig. 5 through 8; the first stage slopes are smaller than the third stage slopes.

If PMF is added to a stage, its velocity $(\Delta \mathrm{V})$ capability, and thus the payload and vehicle GLOW, increases thereby decreasing the amount of $\Delta \mathrm{V}$ required by the other stages. When second stage PMF was added, the first stage was forced to compensate for the mass required to produce that additional second stage performance by increasing its $\Delta \mathrm{V}$ capability. Between the increases in $\Delta \mathrm{V}$ required for the first and second stage, where the $\Delta \mathrm{V}$ requirement was higher for the second stage, consequently the third stage compensated for this change by lessening its $\Delta \mathrm{V}$ requirement.

In comparing the NESC-1 and NESC- 4 configurations, it is interesting that gear ratios are lower for the NESC-4 despite having a better performing upper stage. Although this phenomenon may seem counterintuitive, the trend where lower stages are affected by a change in subsequent stage efficiency has also been noticed in SLS studies. Keep in mind too that the payload capabilities are rather different for the NESC-1 and NESC-4 configurations, $75 \mathrm{lb}_{\mathrm{m}}$ and $142 \mathrm{lb}_{\mathrm{m}}$, respectively.

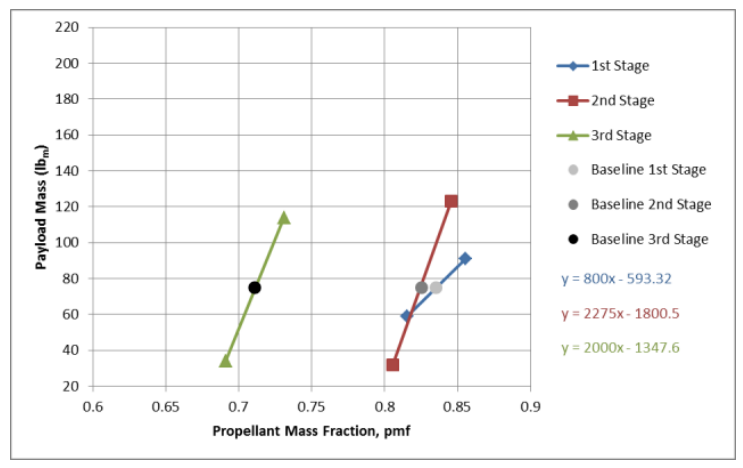

Figure 5. NESC-1 PMF Sensitivity Results

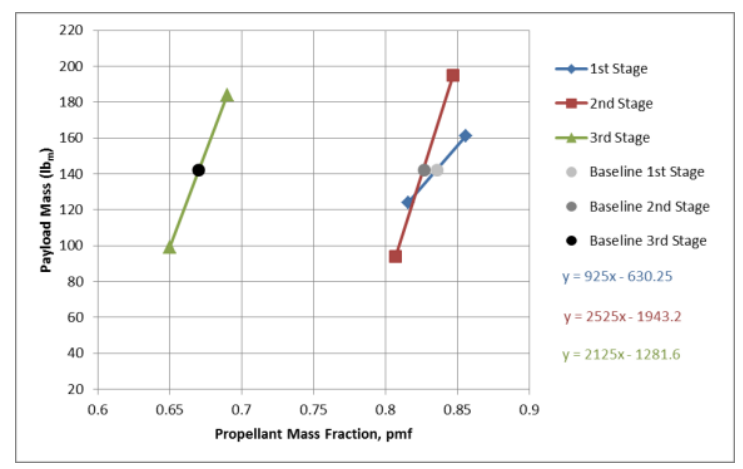

Figure 6. NESC-4 PMF Sensitivity Results 


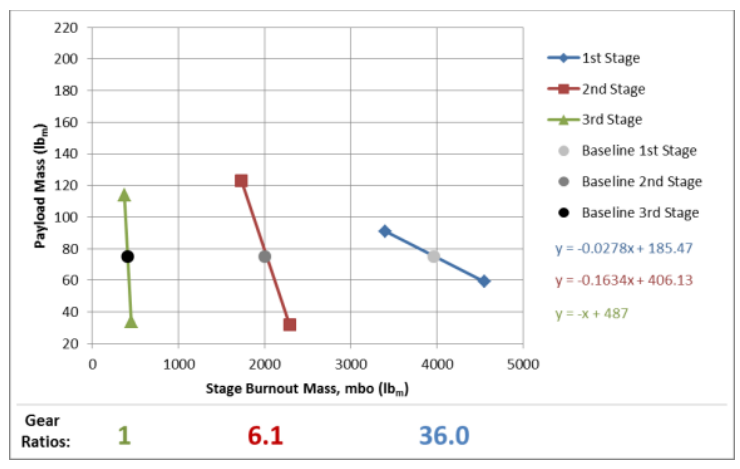

Figure 7. NESC-1 Gear Ratios

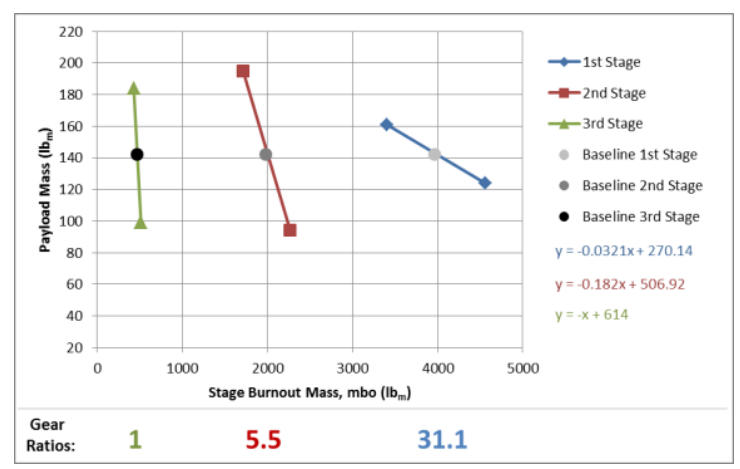

Figure 8. NESC-4 Gear Ratios

The second sensitivity study focused on determining how payload capability would be affected due to changes in stage $I_{\mathrm{sp}}$. While maintaining equal propellant loads in similar stages for each vehicle, in the first and second stages the $I_{s p}$ indicated a higher sensitivity to change for the NESC-4 configuration while the third stage proved more sensitive for the NESC-1 configuration (Fig. 9 and Fig. 10). Despite both configurations having a 1:1 gear ratio for the final stage as is the case for all vehicles, there is lower payload capability sensitivity for the NESC-4 upper stage because it employs a more efficient (higher $\mathrm{I}_{\mathrm{sp}}$ ) propellant combination of $\mathrm{LOX}$ and $\mathrm{LCH}_{4}$ compared to the LOX and RP-1 combination employed in the NESC-1 upper stage. The higher $\mathrm{I}_{\mathrm{sp}}$ compensates for the increased payload mass thus forcing the lower two stages become more sensitive. In other words, employing the same propellant combination throughout the entire vehicle causes $I_{\text {sp }}$ sensitivity to spread more evenly among each of the three stages as in the NESC-1 configuration.

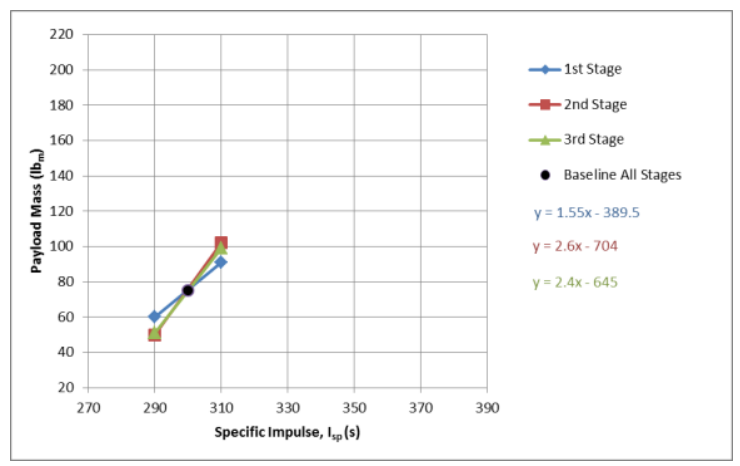

Figure 9. NESC-1 $I_{\text {sp }}$ sensitivity study results.

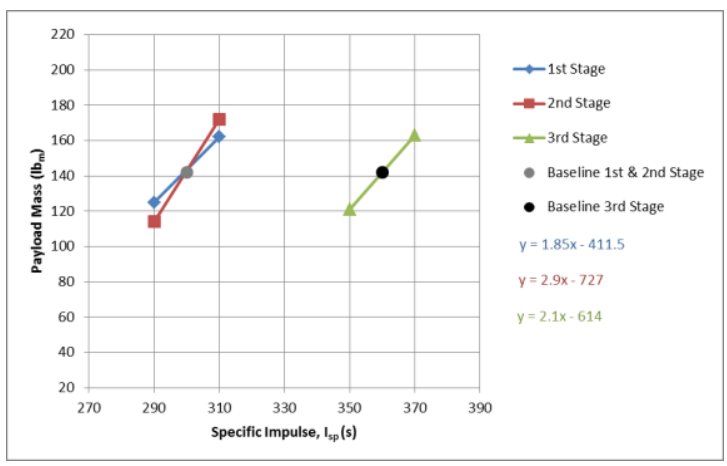

Figure 10. NESC-4 $I_{\text {sp }}$ sensitivity results.

\section{B. NESC-4A Sensitivity and Trade Studies}

As previously mentioned, some smaller entities within the emerging SLV industry are in the process of developing vehicles that employ the $\mathrm{LOX}$ and $\mathrm{LCH}_{4}$ propellant combination, which has a higher ideal $\mathrm{I}_{\mathrm{sp}}$ than $\mathrm{LOX}$ and RP-1 and is also a widely utilized and publicly available commodity especially outside of the aerospace industry. Utilizing $\mathrm{LCH}_{4}$ as an in situ resource has also been an area of interest for NASA when developing transportation type spacecraft. With that said, this SLV study chose to use the NESC-4 vehicle configuration with a LOX and $\mathrm{LCH}_{4}$ upper stage as the baseline for conducting additional trade studies in an effort to reduce overall vehicle cost (Fig. 4).

The first goal was to maximize payload capability of the launch vehicle and could be easily accomplished by decreasing delivery altitude. Initially a circular orbit with an altitude of $200 \mathrm{nmi}$ was chosen as a nominal starting point. As the altitude was decremented from $200 \mathrm{nmi}$ down to $160 \mathrm{nmi}$ (NESC-4B) and then again to $120 \mathrm{nmi}$ (NESC-4C), the payload capability was free to change while the vehicle's GLOW and performance parameters remained fixed. As expected the payload capability increased as the delivery altitude dropped gaining $42 \mathrm{lb}_{\mathrm{m}}$ to achieve a total payload of $206 \mathrm{lb}_{\mathrm{m}}$ (Fig. 11). A $120 \mathrm{nmi}$ circular orbit was the lowest studied as this was the lowest that could still provide a reasonable stay time per vehicle launch cost.

The next series of trade studies focused on reducing vehicle GLOW by targeting the propulsion subsystem as well as long held ACO standards for SF and MGA from studying large launch vehicles. First the propulsion 
subsystem mass was minimized by trading pressure-fed (NESC-4C) with pump-fed systems (NESC-4D). First and second stage propellant tank pressures were reduced from 550 psia to 50 psia and third stage pressure from 250 psia to $50 \mathrm{psia}$. The forward skirt on each stage was shortened to cover only the height of the LOX propellant tank dome since a pump-fed system does not require as much pressurant atop each stage. The engine feed system and Helium pressurant masses were also adjusted down to account for the lower propellant tank pressures. Together these changes totaled a mass savings of approximately $1,000 \mathrm{lb}_{\mathrm{m}}$ and $2.5 \mathrm{ft}$ shorter vehicle length which translated to a payload increase of $125 \mathrm{lb}_{\mathrm{m}}$ (Fig. 12) and a total length of $66.4 \mathrm{ft}$. It was found that employing a pump-fed propulsion system on the upper stage crossed the boundary of diminishing return such that a pressure-fed system actually resulted in higher payload capability. In other words, the mass differential between a pressure-fed engine and a pump-fed engine for low thrust applications (about $1,000 \mathrm{lb}_{\mathrm{f}}$ ) was less than the latest mass estimate for a small pump.

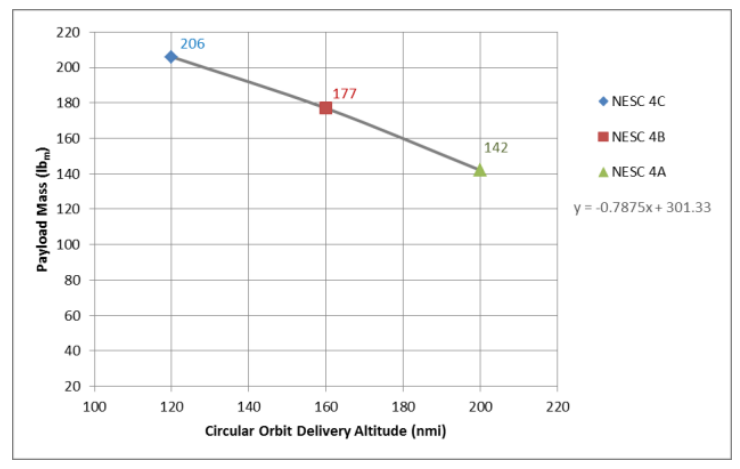

Figure 11. Payload capability results per delivery altitude decrements.

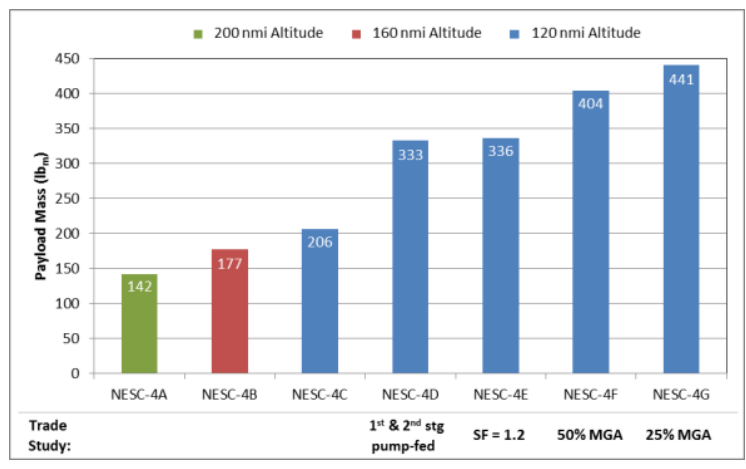

Figure 12. Payload capability results per pump-fed, SF, and MGA trade studies.

The NESC-4E configuration studied the effect of reducing the vehicle's SF from 1.4 to 1.2 across all primary structures. As shown in Fig. 12, the payload increase was minimal as the vehicle only gained $3 \mathrm{lb}_{\mathrm{m}}$ to achieve a total capability of $336 \mathrm{lb}_{\mathrm{m}}$. The resultant increase was low as expected because previous vehicle configurations were already being structurally sized to a minimum gauge wall thickness of approximately $0.036 \mathrm{in}$. at a combined worst case loading condition. Therefore, the vehicle saw very little overall mass savings when adjusting the SF downward especially since the vehicle was being modeled with extremely lightweight IM7/877 graphite epoxy composites.

The standard MGA margins implemented by ACO, 25\% for batteries and avionics components and $18 \%$ for all other vehicle components, were lowered to 50\% (NESC-4F) and 25\% (NESC-4G) of those values to understand how much additional payload capability could be realized if one of these higher risk assumptions were used going forward. Cutting the MGA in half across all vehicle subsystems resulted in a mass savings of approximately $290 \mathrm{lb}_{\mathrm{m}}$ translating to $70 \mathrm{lb}_{\mathrm{m}}$ of additional payload capability while adjusting the MGA to $25 \%$ resulted in a $430 \mathrm{lb}_{\mathrm{m}}$ mass savings and $105 \mathrm{lb}_{\mathrm{m}}$ of additional payload. Although reducing MGA to 25\% of the ACO standard yielded substantial payload increase, the NESC-4F configuration was chosen as the most viable as it was deemed that such a low tolerance for mass growth as in the NESC-4G configuration was considered unrealistic.

The second series of trade studies investigated avenues for vehicle optimization by means of propellant load adjustments (Fig. 13). The first adjustment (NESC-4H) was lowering the first and second stage MR from a starting point of 2.77 to 2.50 . After assessing a variety of existing LOX and RP-1 propulsion systems producing a wide range of thrust levels, the majority employed a MR ranging from approximately $2.25-2.77$, therefore the $\mathrm{MR}=2.50$ was more appropriately analyzed as the nominal case. Manipulating the MR was a feasible option as the vehicle employed only conceptualized engines; however, the vehicle GLOW was held constant such that LOX and RP-1 propellant loads were resized to match the refined MR GR\&A. The payload capability fell only $2 \mathrm{lb}_{\mathrm{m}}$ to a total of $402 \mathrm{lb}_{\mathrm{m}}$ which is considered negligible as this mass differential falls within the noise of the ACO process.

The second adjustment (NESC-4i) reduced the first stage propellant load until the stage jettisoned at ten seconds past the time of maximum dynamic pressure. In previous configurations this GR\&A did not exist and therefore the dynamic pressure event was allowed to float freely, but always occurring prior to first stage separation. Since the second and third stages were not resized to compensate for the first stage propellant removed, the vehicle GLOW dropped significantly, nearly $1,000 \mathrm{lb}$, and the payload capability decreased by $220 \mathrm{lb}_{\mathrm{m}}$ to a total of $182 \mathrm{lb}_{\mathrm{m}}$. Consequently, the vehicle shortened by $11.1 \mathrm{ft}$ to a length of $56 \mathrm{ft}$ while the diameter remained constant. 
This significant propellant load reduction shifted the $\Delta \mathrm{V}$ split such that the third stage accounted for the majority of the $\Delta \mathrm{V}$ capability lost from the first stage.

The third and final adjustment was made through a series of analyses and concluded with the NESC-4N configuration. The second stage fuel tank length was minimized such that its shape was effectively a sphere, or dome-to-dome, but the MR $=2.50$ was maintained. Approximately $3,000 \mathrm{lb}_{\mathrm{m}}$ of propellant were removed from the second stage while only $270 \mathrm{lb}_{\mathrm{m}}$ were added to the third stage. Although some of this exchange was accounted for in the higher third stage $I_{\text {sp }}$ of 360 seconds compared to 300 seconds in the second stage, the payload capability was free to change thereby dropping $66 \mathrm{lb}_{\mathrm{m}}$ to a total of $116 \mathrm{lb}_{\mathrm{m}}$. The second and third stage lengths also changed by $-4.3 \mathrm{ft}$ and $+1.2 \mathrm{ft}$, respectively, keeping in mind that $\mathrm{LCH}_{4}$ is less dense than RP-1, and the majority of the $\Delta \mathrm{V}$ capability shifted from the second to third stage.

The next series of sensitivity studies focused on first and second stage diameter optimization and third stage thrust optimization. Both the first and second stages were twice decremented by step sizes of approximately $0.15 \mathrm{ft}$ while the vehicle GLOW and all performance parameters were held constant as shown in Fig. 14. Each of the three points were plotted and a maximum diameter of $3.30 \mathrm{ft}$ was realized (NESC-4N.4). The vehicle length increased by $13.3 \mathrm{ft}$ to a total of $65.6 \mathrm{ft}$ and gained $40 \mathrm{lb}_{\mathrm{m}}$ of payload capability to reach $156 \mathrm{lb}_{\mathrm{m}}$. A L / D ratio of 20 was considered an upper limit as vehicles in this range would become susceptible to frequency response issues. In this potentially fatal circumstance, the vehicle becomes essentially too bendable where it is then unable to sufficiently react to shifts in its Center of Gravity (CG). As the CG deviates from the longitudinal axis the result is a tumbling affect. The third stage thrust was then analyzed and found to be optimum at 1,200 lbf (NESC-4P) which only gained an additional $3 \mathrm{lb}_{\mathrm{m}}$ of payload (Fig. 15) to achieve $159 \mathrm{lb}_{\mathrm{m}}$. A second stage thrust optimization was conducted but did not ultimately want to change therefore the first stage was already deemed optimized within an error band of $1,000 \mathrm{lb}_{\mathrm{f}}$.

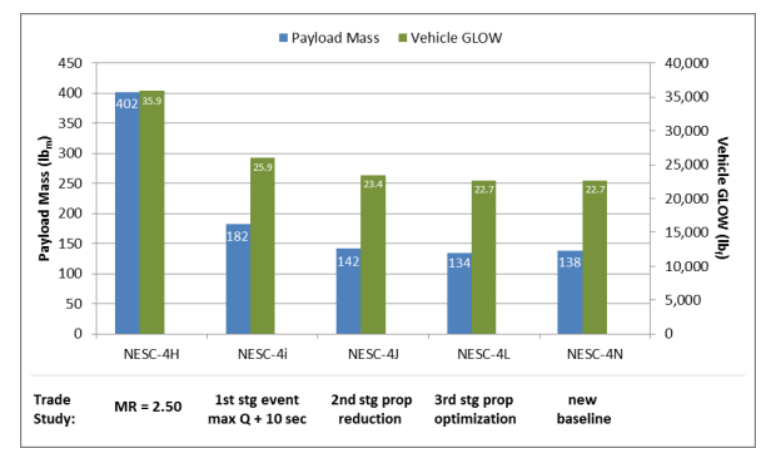

Figure 13. Payload capability and vehicle GLOW per MR and propellant optimization trade studies.

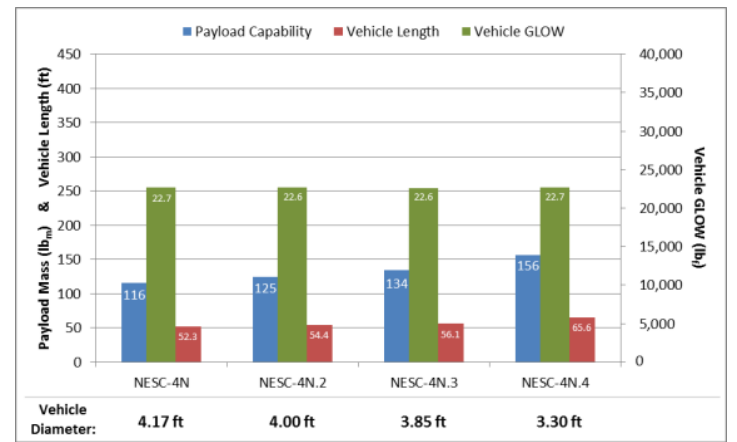

Figure 14. Payload capability results per $1^{\text {st }}$ and $2^{\text {nd }}$ stage vehicle diameter sensitivity study.

The third series of trade studies sought to understand how launch methods, strap-on SRB thrust augmentation, and TVC systems would impact payload capability. To simplify the analysis and allow for a direct comparison between vehicles particularly within this trade study, all launches were fixed to a $28.5^{\circ}$ inclination; however, it is feasible that rail launches could also potentially be performed at other launch sites such as a due east launch out of Wallops Flight Facility (WFF) depending on vehicle GLOW and total length. The first pair of configurations each employed two Mk 70 Mod 1 ER SRBs thus increasing maximum G's from 5.53 to 7.40 (NESC-4Q) and 7.62 (NESC-4Q.2). Launched from a rail at an optimized rail angle, the NESC-4Q configuration employed passive guidance via hollow four fins designed symmetrically with $90^{\circ}$ spacing in order to provide the vehicle with a stability margin of $1.5-2.0$, the distance between the further forward CG and further aft Center of Pressure (CP). The second stage was designed in a similar manner with a stability margin of 1.0. To produce these stability margins, the total fin wetted area between both stages was such that they added an additional $400 \mathrm{lb}_{\mathrm{m}}$ of dry mass compared to the TVC mass estimates for the NESC-4Q.2 configuration; however, payload capability increased substantially from $63 \mathrm{lb}_{\mathrm{m}}$ to $190 \mathrm{lb}_{\mathrm{m}}$. Pitch In addition to performance increase, an important side effect of removing TVC was that range safety ordnances would no longer be required thus substantially reducing operational costs by eliminating the necessity of live charges on the pad and in flight in the event of a TVC failure. Moreover, fins inherently decrease the size of the launch corridor thereby requiring a smaller clearance of surrounding marine vessels. In other words, the vehicle would surpass structural limitations before breaching the bounds of the launch corridor as opposed to flying a ballistic trajectory upon TVC failure. 
The second pair of configurations each employed four Mk 70 Mod 1 ER SRBs and resulted in an increase of maximum G's from 5.53 to 10.89 (NESC-4R) and 11.24 (NESC-4R.2). The NESC-4R configuration was modeled and flown similar to the NESC-4Q configuration in that in employed first and second stage passive guidance via fin stabilization and was launched from a rail also at an optimized rail angle. After removing the first and second TVC masses and building in fins, the vehicle gained about $580 \mathrm{lb}_{\mathrm{m}}$ but further grew in payload capability from $72 \mathrm{lb}_{\mathrm{m}}$ to 235

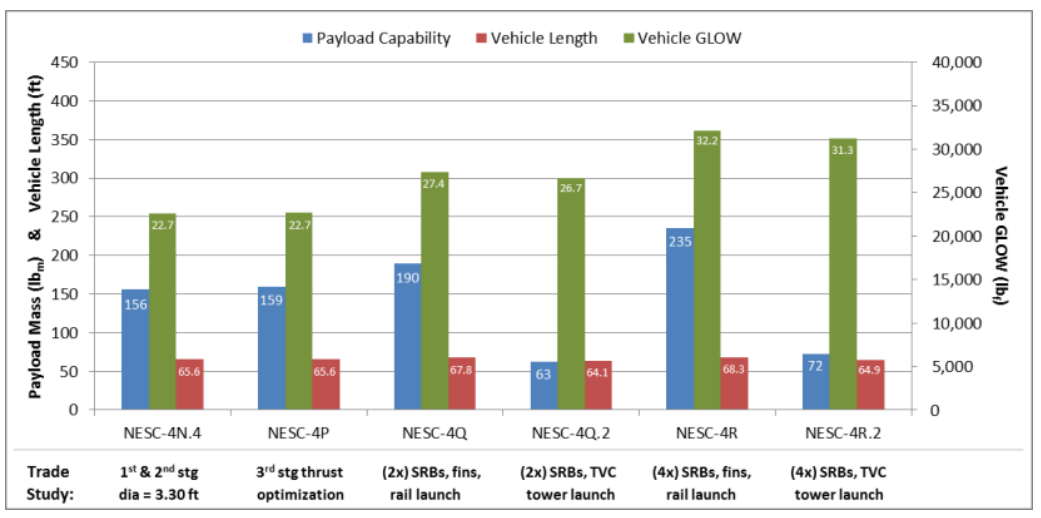

Figure 15. Payload capability results per thrust optimization, SRB and guidance, and launch method trade studies.

$\mathrm{lb}_{\mathrm{m}}$. In both the NESC-4Q and NESC-4Q.2 pair and the NESC-4R and NESC-4R.2 pair of configurations the primary structure did not noticeably increase due to fins. If the NESC-4Q and NESC-4R configurations are compared it is evident that maximum dynamic pressure largely increased from 1,900 psf to 2,800 psf which did however cause a $200 \mathrm{lb}_{\mathrm{m}}$ increase in primary structure mass.

The final study, shown in Fig. 16, aimed at reducing the first and second stage propellant loads of the NESC-4P configuration until a $100 \mathrm{lb}_{\mathrm{m}}$ payload capability was reached in an effort to see how small of a GLOW could be achieved (NESC-4T). In summing both stages, a total of $4,100 \mathrm{lb}_{\mathrm{m}}$ of liquid propellant was removed equaling a $7.6 \mathrm{ft}$ reduction in overall vehicle length to a total of $58.0 \mathrm{ft}$. Keeping in mind that two SRBs were added between the NESC-4P and NESC-4T configurations, the payload capability dropped from $159 \mathrm{lb}_{\mathrm{m}}$ to $98 \mathrm{lb}_{\mathrm{m}}$. Without the addition of any thrust augmentation the NESC-4P configuration, which was the smallest vehicle analyzed during this study, achieved PMFs of 0.82, 0.84 and 0.71 for the first, second and third stages, respectively. The NESC-4T configuration which yielded the

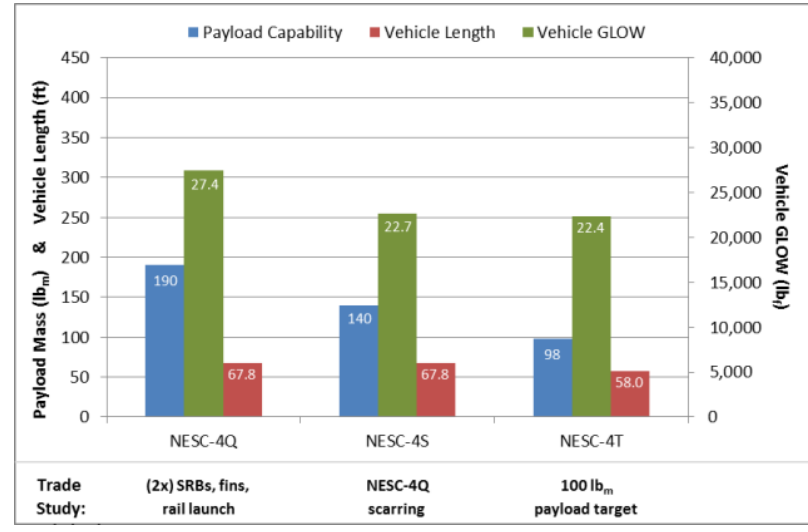

Figure 16. Payload capability results per SRBs and guidance, original scarring, and $100 \mathrm{lb}$ payload target trade studies. smallest payload with respect to GLOW achieved PMFs of 0.80, 0.82 and 0.70 for the first, second and third stages, respectively. The $\Delta \mathrm{V}$ split with respect to both configurations was such that the third stage produced the majority of the velocity.

\section{Lessons Learned}

Analysis has shown that in order to achieve a lightweight launch vehicle with an optimized payload capability, physics targets one with a maximum L / D ratio. A longer vehicle with a relatively small cross-sectional area inherently shifts a higher percentage of the vehicle's dry mass to the propellant tanks than in an alternative design. This occurs because the forward and aft skirts as well as intertanks will automatically become shorter with a reduction in cross-sectional area since domes will shrink in overall size and mass. It is also important not to surpass the maximum L / D ratio as it will become increasingly difficult for active guidance systems to accurately steer the vehicle during ascent consequently creating an unstable trajectory.

\section{Conclusion}

There are a number of small entities emerging across the United States with the intent on building low cost SLVs capable of inserting payloads on the order of $1-100 \mathrm{lb}_{\mathrm{m}}(0.5-50 \mathrm{~kg})$ into LEO. With technology capable of constructing SLVs becoming more widely available every day and at lower cost, NASA sought to expand its knowledgebase from solely large launch vehicles with primarily medium to heavy lift capability, to SLVs that could one day provide a cost effective solution for raising Technology Readiness Levels (TRLs). It is evident that 
facilitating growth in this area could also help NASA provide higher education institutions especially with high frequency launches and thus extended flight time for CubeSat sized experiments at reduced cost.

NASA has continued to see an increase in proposals submitted by small entities that describe SLV concepts capable of delivering payloads within the aforementioned range. Despite advancements in composites and avionics technologies over the past decade, it is clear the majority of these proposals are predicting very optimistic stage PMFs particularly for upper stages, in the range of $0.85-0.90$, some stages of which are much smaller than even those used in this study. Keeping in mind key INTROS MERs were refined prior to this study, the NESC vehicle concepts are predicting lower PMFs ranging from $0.65-0.78$ for third stages to $0.79-0.88$ for first stages. The NESC vehicles are also assuming high $\mathrm{I}_{\mathrm{sp}}$ propulsion systems and extremely lightweight graphite epoxy composite primary structures across the entire vehicle. This study concluded the necessity for a substantial amount of additional propellant load to graduate from sounding rocket capability to a vehicle that can not only deliver small payloads to LEO but one that can provide sufficient $\Delta \mathrm{V}$ to sustain orbit. Furthermore, it proved that SLVs are just as sensitive to changes in vehicle architecture as heavy lift vehicles.

To develop a viable SLV capable of sustaining orbit requires just as much attention to detail, if not more so, than large heavy lift vehicles. It is important to be aware that designing a SLV solely based on the ideal rocket equation will not suffice; like any project, it requires keen accounting of all mass properties, a detailed full vehicle structural analysis, and a well-defined trajectory from liftoff to deorbit.

In order to achieve a low cost, self-sustained SLV industry there is work still to do in helping the commercial sector gain experience in all that is required to design, build and fly SLVs capable of safely putting small payloads into LEO. This study aided NASA in understanding approximately how small of a launch vehicle is required to pursue this endeavor and what it would cost to initiate growth in this area.

\section{References}

\footnotetext{
1“Delta IV Payload Planner's Guide," Sept. 2007, URL: www.ulalaunch.com/site/.../guides/DeltaIVPayloadPlannersGuide2007.pdf

${ }^{2}$ Creech, D. M., Threet, G. E., Jr., Philips, A. D., and Waters, E. D., "Launch Vehicle Demonstrator Using Shuttle Assets," AIAA Space 2011 Conference, AIAA 2011-7283, Long Beach, CA, 2011.

${ }^{3}$ Waters, E. D., Threet, G.E., Jr. Philips, A.D., and Beers, B. R., "The MSFC Advance Concepts Office Launch Vehicle Design Process," AIAA Space 2013 Conference, San Diego, CA, 2011 (submitted for publication).

${ }^{4}$ Hill, P. G., and Peterson, C. R., Mechanics and Thermodynamics of Propulsion, $2^{\text {nd }}$ ed., Addison-Wesley, 1992, pp. 571.

${ }^{5}$ Turner, R. E., and Hill, C.K., "Terrestrial Environment (Climactic) Criteria Guidelines for Use in Aerospace Vehicle Development," NASA TM-82473, 1982.

6“'Altas V Launch Services User's Guide,” Mar. 2010, URL: www.ulalaunch.com/site/docs/product.../guides/AtlasVUsersGuide2010.pdf
} 